\title{
JURAMENTO O PROMESA DE JUECES Y MAGISTRADOS
}

\author{
CARMEN CASTAÑÓN JIMÉNEZ
}


SUMARIO

1. NOCIONES PRELIMINARES SOBRE EL JURAMENTO O PROMESA EN EL PODER JUDICIAL. 2. JURAMENTO O PROMESA DE JUECES Y MAGISTRADOS. 2.1 Carrera judicial. 2.2 Jueces de paz. 2.3 Suplencia y sustitución. 2.3.1 Magistrados suplentes, magistrados y jueces sustitutos y de apoyo. 2.3.2 Sustitutos de los jueces de paz. 2.3.3 Jueces en prácticas como jueces sustitutos con funciones jurisdiccionales plenas. 3. ÓRGANOS DE GOBIERNO. 3.1 Consejo General del Poder Judicial. 3.2 Salas de gobierno de órganos jurisdiccionales. 4. CONCLUSIONES. 


\title{
JURAMENTO O PROMESA DE JUECES Y MAGISTRADOS
}

\author{
CARMEN CASTAÑÓN JIMÉNEZ *
}

\section{NOCIONES PRELIMINARES SOBRE EL JURAMENTO O PROMESA EN EL PODER JUDICIAL}

Desde tiempos inmemoriales el ser humano ha recurrido al juramento como garantía de su palabra, prestada bien como testimonio, bien como compromiso de un comportamiento futuro. Según la definición ya clásica de Grossi ${ }^{1}$, el juramento es «el compromiso, asumido en forma expresa y solemne mediante la apelación a valores éticos profusamente difundidos y compartidos en la comunidad, según un rito y una fórmula prefijados, de seguir en el futuro un comportamiento inspirado en la fidelidad y lealtad respecto a los deberes de orden general o particular».

El juramento se configura así como una garantía adicional a la propia palabra e incluso a las normas que puedan regir el caso al que se aplica. A las consecuencias jurídicas que puedan resultar de su quebrantamiento se añade la impetración del castigo o maldición divina (López Guerra²). En su versión laica de promesa, aunque también plenamente aplicable al juramento, supone comprometer el propio honor en el cumplimiento de lo que es objeto del juramento o promesa.

La cuestión de si el juramento es meramente simbólico es muy vieja. Valga decir que el juramento tiene capacidad psicológica de crear compromiso y tiene significado ético para la mayoría de las personas. En todo caso, el juramento es

* Cuerpo Superior de Administradores Civiles del Estado. Doctora en Derecho y Ciencias Sociales. Escuela Internacional de Doctorado. Universidad Nacional de Educación a Distancia (UNED). Calle Bravo Murillo, 38. 28015 Madrid. Correo electrónico: carmen@ castanon.es

${ }^{1}$ Grossi, P. (1970), «Giuramento (Diritto Constituzionale)», en Enciclopedia del Diritto, XIX, Milán, Giuffré, pág. 144.

2 López Guerra, L. (1997), «Artículo 61. Juramento», en Alzaga Villaamil, O. (dir.), Comentarios a la Constitución española de 1978, Vol. V, Madrid, Cortes Generales, Edersa, pág. 206. 
el mayor compromiso ético posible: incluso para quienes consideran vacía este tipo de promesa, es al menos tan válido como cualquier otro tipo de compromiso ético (Steen y Rutgers ${ }^{3}$ ).

En el ámbito del empleo público se concreta en un contenido globalmente muy bien definido: el deber de fidelidad o, lo que es lo mismo, el deber de lealtad $\left(\right.$ Gálvez $\left.{ }^{4}\right)$. El deber de fidelidad «estándar» sería el derivado del art. $103 \mathrm{CE}$, vinculado por tanto a la necesaria objetividad e imparcialidad de la Administración. Sin embargo, se exige un deber de fidelidad «activa» a determinadas categorías de empleados públicos que gozan de un estatuto peculiar, con determinadas obligaciones hacia la Constitución que normalmente incrementan su grado de exigencia de fidelidad.

Es el caso de los jueces y magistrados, puesto que su posición respecto a la Constitución es un tanto singular respecto a la de los demás funcionarios en cuanto que a los jueces les corresponde, en el ejercicio de su función misma, la aplicación constante de la Constitución $\left(\right.$ Embid $\left.^{5}\right)$. Sobre el alcance y significado del deber de fidelidad activa de los jueces, expresado en su juramento, se pronuncian las SSTS 5076/1999 (FJ 6..$^{\circ}$ y 921/2006 (FJ 6. ${ }^{\circ}$ ):

Dicho de otro modo: Jueces y Magistrados, además de deber ejercer correctamente la función jurisdiccional, vienen obligados, mientras permanezcan en activo, esto es, en situación de habilitación legal para el ejercicio de dicha función, vienen obligados -se repite- a cumplir con el deber de lealtad constitucional. $Y$, en virtud del mismo, a no realizar ninguna clase de conductas que quebranten esa confianza social en el Poder Judicial que constituye elemento básico del sistema democrático.

La dicción de la fórmula del juramento o promesa, recogida en el artículo 318 de la LOPJ, aboga en favor de esas dos categorías diferenciadas de obligaciones. Habla, de una parte, de "guardar», $y$, de otra, de «hacer guardar» fielmente la Constitución.

El «hacer guardar» va claramente referido a la función jurisdiccional, pues apunta hacia exigencias a terceros en orden al cumplimiento constitucional. Pero el "guardar» tiene una clara connotación de compromiso de conducta personal mientras se ostente ante la sociedad la titularidad de la potestad jurisdiccional.

Estos pronunciamientos del TS podrían prestarse a crítica, pues difícilmente puede concluirse de manera tan automática que del juramento puedan dimanar obligaciones distintas de las que ya surgen del principio de legalidad, máxi-

${ }^{3}$ Steen, T. S. y Rutgers, M. R. (2011), «The double-edged sword». Public Management Review, 13:3, 358, DOI: 10.1080/14719037.2011.553262

${ }^{4}$ Gálvez Montes, J. (1975), «El juramento de fidelidad del funcionario». Documentación Administrativa, 167, pág. 43.

5 Embid Irujo, A. (1987), La fidelidad de los funcionarios a la Constitución (Un estudio de los Derechos alemán y español), Madrid, INAP, pág. 177. 
me cuando la argumentación descansa sobre un concepto tan indeterminado como la «confianza social». Pero hay que tener presente que la eficacia del juramento no puede sostenerse exclusivamente en el plano jurídico, sino que es necesario apelar simultáneamente a un orden ético y social en el que sea posible la definición de un estándar de conducta superior exigible de quienes son investidos de potestades en virtud de una Constitución a la que se deben muy especialmente. Esa relación de especial sujeción, diferente de la sujeción genérica proclamada en el art. 9.1 CE, es la clave para entender que por vía del juramento no se adquieren nuevos deberes distintos a los exigidos por las leyes, pero sí un compromiso de especial observancia en el modo de proceder, a la manera de «la mujer del César». Sólo así puede entenderse la «confianza social», que apela a las expectativas de los ciudadanos respecto de quienes están investidos de potestad para decidir sobre su libertad y sus bienes.

De este modo encaja la función de «zócalo antropológico» de la identidad de jueces y magistrados, que con la prestación de juramento o promesa en audiencia aceptan situar su función en el horizonte de una promesa de fidelidad a sus deberes y se ponen, en cierto modo, en situación de ser juzgados a su vez (Salas $\left.{ }^{6}\right)$.

Vaya por delante que el empleo del juramento o promesa en el ámbito del poder judicial es más amplio que el exigido a jueces y magistrados, pues abarca también el exigido a otros colaboradores (Ministerio Fiscal, Abogados y Procuradores, Graduados Sociales, Policía Judicial, representación y defensa del Estado y demás entes públicos), la estructura paralela de la jurisdicción militar (en la que convive la jura de bandera con los juramentos judiciales) y el despliegue del juramento en el ámbito procesal (Testigos, Peritos, Traductores e Intérpretes Judiciales y Tribunal del Jurado). En este trabajo nos centramos estrictamente en las implicaciones del juramento o promesa exigido a jueces y magistrados.

Pero antes de adentrarnos en el objeto de estudio, un breve apunte de Derecho comparado para ilustrar cuán constante es la exigencia del juramento en el ámbito de la judicatura. El ejemplo paradigmático sería el estadounidense, dada la larga y culturalmente arraigada tradición juradera de ese país. La Constitución de los Estados Unidos contiene en su Artículo VI un mandato genérico de juramento o promesa de «sostener» esa Constitución para Senadores, Representantes, miembros de las Asambleas Legislativas de los diversos estados, así como todos los funcionarios ejecutivos y judiciales, especificando que no se podrá exigir «requisito religioso alguno para desempeñar ningún cargo o empleo, retribuido o de confianza, bajo la autoridad de los Estados Unidos». Además, los magistra-

${ }^{6}$ SAlas, D. (2009), La ética del juez en la era de la globalización, Madrid, Cuadernos Digitales de Formación, Consejo General del Poder Judicial, pág. 12. 
dos del Tribunal Supremo deben prestar el juramento regulado en el Título 28, Capítulo I, Parte 453 del Código de los Estados Unidos: Yo, (NOMBRE), juro (o prometo) solemnemente que administraré justicia sin importarme a quién, tratando por igual a ricos y pobres, y que cumpliré y ejecutaré fiel e imparcialmente las obligaciones que me correspondan como (TIITULO\} de conformidad con la Constitución y las leyes de los Estados Unidos. Con la ayuda de Dios ${ }^{7}$. Los jueces federales prestan el juramento prescrito por la Ley Judicial de 1789: Juro (o prometo) solemnemente que administraré justicia sin importarme a quién, tratando por igual a ricos y pobres, y que cumpliré y ejecutaré fiel e imparcialmente las obligaciones que me correspondan, conforme a mis mejores babilidades y entendimiento, de acuerdo con la Constitución y las leyes de los Estados Unidos. Con la ayuda de Dios.

En países más cercanos a nuestro entorno también se exige juramento a jueces y magistrados antes de iniciar el ejercicio de la potestad jurisdiccional. Así, por ejemplo, Francia: Juro cumplir leal y fielmente mis funciones, guardar religiosamente el secreto de las deliberaciones y conducirme en todo como un digno y leal magistra$d 0^{9}$ (art. 6 de la Ordenanza 58-1270 de 22 de diciembre de 1958, por la que se aprueba la Ley Orgánica sobre el Estatuto de la Magistratura). También Alemania: Juro la magistratura, con fidelidad a la Ley Fundamental de la República Federal de Alemania y administrar la ley según mi mejor saber y entender, sin importar a quién, y servir sólo a la verdad y a la justica, con la ayuda de Dios ${ }^{10}$ (art. 28 de la Ley Alemana de la Judicatura). En ambos casos se trata de juramentos laicos, a pesar de lo que su redacción pueda dar a entender.

En nuestro país, la Ley Orgánica 6/1985, de 1 de julio, del Poder Judicial ${ }^{11}$ (LOPJ) contiene nada menos que diecisiete menciones expresas al juramento o promesa o al acto de jurar o prometer en el ámbito del poder judicial.

7 I, (NAME), do solemnly swear (or affirm) that I will administer justice without respect to persons, and do equal right to the poor and to the rich, and that I will faithfully and impartially discharge and perform all the duties incumbent upon me as (TITLE) under the Constitution and laws of the United States. So belp me God.

${ }^{8}$ I, (NAME), do solemnly swear (or affirm) that I will administer justice without respect to persons, and do equal right to the poor and to the rich, and that I will faithfully and impartially discharge and perform all the duties incumbent upon me under the Constitution and laws of the United States. So belp me God.

${ }^{9}$ Je jure de bien et fidèlement remplir mes fonctions, de garder religieusement le secret des délibérations et de me conduire en tout comme un digne et loyal magistrat.

${ }^{10}$ Ich schwöre, das Richteramt getreu dem Grundgesetz für die Bundesrepublik Deutschland und getreu dem Gesetz auszuïben, nach bestem Wissen und Gewissen obne Ansehen der Person zu urteilen und nur der Wabrheit und Gerechtigkeit zu dienen, so wahr mir Gott helfe.

11 Versión consolidada vigente desde 28 de octubre de 2015. 
González $^{12}$ observa que el que la LOPJ reitere la obligación de que los miembros de la carrera judicial lleven a cabo su misión conforme a la CE contrasta con el art. $117 \mathrm{CE}$, que les somete «únicamente al imperio de la ley», si bien a renglón seguido remite al mandato general del art. 9.1 CE, que vincula a todos los poderes públicos, incluido el judicial, a la sujeción a la CE. Precisamente por este motivo prescribe una fórmula de juramento o promesa diferente de la prevista para el resto de funcionarios.

En efecto, si hay un ámbito en el Estado de derecho que exige una especial protección de la confianza que en él depositan los ciudadanos, es el de la Justicia. Cuando un ciudadano acude ante un juez, es porque se ve compelido a depositar su confianza en un tercero porque la vida en sociedad así lo requiere como evolución de tomarse la justicia por la propia mano. Precisamente porque esa confianza es forzada, los avances democráticos garantizan una separación de poderes plena, en la que jueces y magistrados son independientes, inamovibles, responsables y sometidos únicamente al imperio de la ley (art. 117.1 CE).

El juramento de jueces y magistrados es un mecanismo de refuerzo de la independencia judicial porque la sujeción al imperio de la ley no se identifica sólo con la sujeción genérica de ciudadanos y poderes públicos «a la Constitución y al resto del ordenamiento jurídico» (art. 9.1 CE), sino que va más allá, ya que, al exigirse un compromiso público y solemne de «guardar y hacer guardar la Constitución» se está subrayando que ninguno de los otros poderes que dimanan de la misma puede alterar la independencia judicial. La sujeción es exclusivamente a la Constitución, no sólo por imperativo legal, sino además por vínculo de juramento.

Valga como espejo de esta afirmación la interpretación que se hace del juramento público por antonomasia, el del Presidente de los EEUU: la terminología constitucional que obliga al Presidente a ejecutar «el cargo» más que las leyes, es la prueba de los poderes implícitos de la prerrogativa presidencial en la Constitución ${ }^{13}$.

Pero además de esa garantía ad extra, el juramento o promesa opera como una garantía adicional ad intra, en la medida en que la CE, a través del desarrollo que de ella ha hecho la LOPJ, busca el compromiso explícito y público de las personas que integran el poder judicial, sometiéndolas al requisito de juramento o promesa previo al desempeño del cargo. Por eso el juramento de jueces y

12 González Hernández, E. (2004), «Juramento y lealtad a la Constitución». Revista de Derecho Político, 60, pág. 236.

${ }^{13}$ Nelson, M. (ed.) (2008), Guide to the Presidency ( $4^{\text {th }}$ ed.). Washington, DC: A Division of Congressional Quarterly Inc. 
magistrados va más allá de la mera sumisión a la ley, puesto que «está atravesado por una tensión entre un polo ético (la dignidad, el honor, la conciencia, la lealtad...) y un polo político, que recuerda las condiciones de aplicación de la ley (el secreto, el respeto de la ley, el servicio a la nación...). El juramento sella la relación con el ámbito de la política y la esfera de la conciencia. Sin dejar de ser un ritual de incorporación a un organismo, se convierte en una forma de asignación de responsabilidad ante otros» $\left(\right.$ Salas $\left.^{14}\right)$.

\section{JURAMENTO O PROMESA DE JUECES Y MAGISTRADOS}

Si bien las funciones jurisdiccionales en los Juzgados y Tribunales de los diferentes órdenes se ejercen únicamente por jueces y magistrados profesionales, que forman la carrera judicial, la LOPJ prevé la posibilidad de que otro tipo de personal ejerza funciones jurisdiccionales sin pertenecer a la carrera judicial (art. 298). Se trata de los magistrados suplentes, los que sirven plazas de jueces como sustitutos, y los jueces de paz y sus sustitutos. A todos ellos la LOPJ les habilita para ejercer funciones jurisdiccionales en términos concretos, sin carácter de profesionalidad y con inamovilidad temporal. Es por ello que a la hora de analizar en detalle el juramento o promesa de jueces y magistrados sea necesario distinguir entre carrera judicial propiamente dicha, jueces de paz y sustitutos de unos y otros, así como los jueces y magistrados que integran los órganos de gobierno del poder judicial.

\subsection{Carrera judicial}

Conforme al art. 298 LOPJ, la carrera judicial la forman los jueces y magistrados profesionales, encargados por la CE de administrar en nombre del Rey la justicia que emana del pueblo. Para poder desempeñar tan importante función gozan de independencia, inamovilidad, responsabilidad, sometimiento exclusivo al imperio de la Ley y no podrán ser separados, suspendidos, trasladados ni jubilados sino por alguna de las causas y con las garantías previstas en la Ley (art. $117 \mathrm{CE}$ ).

La LOPJ contiene numerosas menciones del juramento o promesa aplicables a jueces y magistrados. También abundan las referencias en el Reglamento de la Carrera Judicial (RCJ, Acuerdo de 28 de abril de 2011, del Pleno del CGPJ, por el que se aprueba el Reglamento 2/2011 de la Carrera Judicial) y el Reglamento de honores, tratamientos y protocolo en los actos judiciales solemnes (RHTP, Acuerdo de 23 de noviembre de 2005, del Pleno del CGPJ). Es de por sí reve-

14 Salas, D. (2009), Op. cit., pág. 12. 
lador el hecho de que tanto el legislador mandatado por la CE como el Consejo General del Poder Judicial (CGPJ), únicos con capacidad normativa sobre jueces y magistrados, muestren tanto interés por el juramento o promesa.

Como señala el preámbulo del RHTP, «la regulación de los honores, los tratamientos y el protocolo no constituye en puridad una cuestión de imagen, sino ante todo, de adecuada ubicación del Poder Judicial, de sus integrantes y órganos de gobierno en el seno de las relaciones institucionales, haciendo posible la plasmación visual del rango y régimen constitucional del Poder Judicial y su solemnidad y respetabilidad como Poder del Estado, ante los ciudadanos y el resto de los Poderes e Instituciones». El acto de jura o promesa constituye un acto gubernativo judicial al que se anuda «no un valor puramente simbólico, sino también una relevancia normativa. (...) Su regulación viene a recoger lo que constituyen hoy prácticas habituales, si bien unificando y aclarando los aspectos más controvertidos».

Así, el art. 318 LOPJ es cristalino al imponer dos obligaciones a todos los miembros de la carrera judicial. La primera, prestar juramento o promesa antes de posesionarse del primer destino y también cuando se ascienda de categoría en la carrera. La segunda es la obligación de emplear una determinada fórmula de juramento o promesa, fijada en sus términos literales en el propio tenor del precepto:

Juro (o prometo) guardar y hacer guardar fielmente y en todo tiempo la Constitución y el resto del ordenamiento jurídico, lealtad a la Corona, administrar recta e imparcial justicia y cumplir mis deberes judiciales frente a todos.

Nótese que ambas obligaciones subrayan un agravamiento del requisito de juramento o promesa de jueces y magistrados frente al exigido a otros cargos o empleos públicos. Por una parte, se exige no sólo al ingreso en la carrera judicial, sino en cada ascenso de categoría ${ }^{15}$. Comoquiera que las categorías son tres (juez, magistrado y magistrado del Tribunal Supremo), la exigencia no supone una carga excesiva y en cambio sí contribuye a realzar la importancia del ascenso, que bien merece una renovación del compromiso público con el fiel desempeño del cometido al que sirven.

Pensemos, por ejemplo, que en virtud del art. $61 \mathrm{CE}$ el Príncipe heredero está obligado a prestar juramento en su condición de tal, y luego debe prestar el

15 El debate en torno a la exigencia de renovación del juramento no es desconocido en Derecho comparado. Por ejemplo, en 2001 se debatió una proposición de ley en Francia en la que se trataba de incorporar el juramento en cada ascenso de categoría. La proposición no prosperó, pero no por desechar las razones que la animaban (razones de ensalzamiento del compromiso con los valores constitucionales), sino porque se estimó que dejando la ceremonia del juramento como un acto único en la carrera judicial se contribuía más al fin buscado. 
juramento regio propiamente dicho al adquirir la condición de Rey. Es cierto que, como apunta Torres del Moral ${ }^{16}$, «parece demasiado jurar», pues, aparte de haberlo prestado como Príncipe de Asturias, puede haberlo suscrito como Regente (art. 59.2 CE). Pero López Guerra ${ }^{17}$ considera que se trata de una práctica que enlaza directamente con la ya existente en el Antiguo Régimen, si bien configurada en forma inversa a la forma en que se llevaba a cabo en la Monarquía pre-constitucional. En cualquier caso, se constata «la conveniencia de que conste la adhesión del heredero a los principios constitucionales, dada la posibilidad de que, aun antes de ser Rey, sea llamado al ejercicio de funciones públicas por disposición legal o constitucional».

Por otra parte, la fórmula de juramento judicial queda fijada de manera directa y literal, entrecomillada, y no de manera indirecta como es habitual en otros juramentos o promesas, en los que es más frecuente encontrarse preceptos genéricos como «tomarán posesión de su cargo previo juramento o promesa de fidelidad a la Constitución». Además, al quedar fijada en una norma con rango de ley, y además orgánica, la fórmula goza de gran estabilidad.

Otro rasgo interesante de la regulación del juramento o promesa de jueces y magistrados es el plazo, que se señala como distinto e independiente del plazo para la toma de posesión. Como regla general, el art. 319.1 LOPJ fija un plazo de veinte días naturales para presentarse a tomar posesión de sus respectivos cargos, contados a partir del día siguiente a la publicación de su nombramiento en el Boletín Oficial del Estado (BOE). El plazo para prestar juramento o promesa no viene fijado como tal, pero al tratarse de un requisito necesariamente previo a la toma de posesión, se deduce que el plazo para prestarlo es inferior a veinte días.

Ahora bien, a lo largo de su carrera profesional, un juez o magistrado desempeñará diversos cargos que no requieran prestar juramento o promesa, puesto que sólo se exige cuando el desempeño de los cargos coincida con el nuevo ingreso o con un cambio de categoría profesional. Por ello, el art. 319 LOPJ, que en puridad regula la toma de posesión, incorpora dos salvedades al plazo posesorio y por ende de juramento o promesa. En primer lugar, acorta a ocho días el plazo de toma de posesión para los destinados en la misma población en que hubieran servido el cargo. En segundo lugar, quienes hayan de jurar o prometer el cargo (por tratarse de un primer destino o por coincidir con un ascenso de categoría profesional, o bien algún cargo de órgano de gobierno judicial que así lo exija) tomarán pose-

16 Torres del Moral, A. (1997), El Principe de Asturias. Su estatuto jurídico. Madrid: Congreso de los Diputados, pág. 87.

17 Op. Cit. Págs. 214-215. 
sión dentro de los tres días siguientes al del juramento o promesa. Sin perjuicio de todo ello, el CGPJ podrá prorrogar tales plazos, mediando causa justa.

La separación de autoridades ante las que posesionarse y prestar juramento o promesa subraya la independencia de los actos. Con carácter general, la posesión se realiza en el órgano al que fuesen destinados, mientras que el juramento o promesa se presta ante el órgano de gobierno correspondiente.

Así, los jueces prestarán el juramento o promesa, cuando proceda, ante la Sala de Gobierno del Tribunal o Audiencia a que pertenezca el juzgado para el que hayan sido nombrados, en audiencia pública (art. 321.1 LOPJ). La posesión será en el juzgado al que fueren destinados, en audiencia pública y con asistencia del personal del juzgado, siendo el juez que estuviere ejerciendo la jurisdicción el encargado de darle la posesión (art. 321.2 LOPJ).

Por su parte, la toma de posesión de los Presidentes, Presidentes de Sala y magistrados de Tribunales y Audiencias se hará en audiencia pública ante la Sala de Gobierno del tribunal al que fueren destinados o ante la del Tribunal Superior de Justicia en la Comunidad Autónoma correspondiente (art. 320.1 LOPJ). Nada se explicita sobre la autoridad ante la cual se prestará juramento o promesa, en caso necesario, pero se deduce fácilmente que serán las mismas, tal y como se recoge de cara a los magistrados del Tribunal Supremo y de los Tribunales Superiores de Justicia que fuesen nombrados sin haber pertenecido con anterioridad a la carrera judicial (art. 320.2 LOPJ).

Otro factor que llama la atención sobre la configuración del juramento o promesa como requisito constitutivo es la obligación de comunicación que se impone al Presidente del Tribunal o Audiencia de dar cuenta al CGPJ del juramento o promesa y posesión o, en su caso, del transcurso del tiempo sin hacerlo (art. 322.2 LOPJ).

Es relevante por cuanto la sanción a la falta de juramento o promesa es contundente: se entiende como renuncia al cargo y a la carrera judicial (art. 322.1 LOPJ). Ciertamente, si se alega «justa causa» o «justo impedimento», apreciado por el CGPJ a solicitud del interesado, cabe la posibilidad de rehabilitación del renunciante (art. 323.2 LOPJ). Pero incluso en ese supuesto el rehabilitado deberá presentarse a prestar juramento o promesa o posesionarse de su cargo en el plazo que se señale, que no podrá ser superior a la mitad del plazo normal (art. 323.2 LOPJ).

La obligación de comunicación del juramento o promesa, si bien se entiende como un acto debido para el que el Presidente del Tribunal o Audiencia respectivo se erige en fedatario a efectos de dejar constancia del cumplimiento del requisito, suscita la duda de si dicha constancia distingue entre juramento y promesa. Es decir, si queda registrado si el juez o magistrado optó por jurar o prometer, con las correspondientes posibles consecuencias en cuanto a su libertad 
religiosa. Las grabaciones cada vez más frecuentes de estos actos dificultan el archivo mediante fórmula genérica de cumplimiento del «juramento o promesa», sin indicación sobre la inclinación del interesado. Comoquiera que la libertad religiosa tiene la doble vertiente positiva y negativa, no cabe apreciar vulneración de la libertad como tal. Entendemos más bien que la cuestión debe plantearse en términos de por qué habría de ser relevante el modo de prestación del compromiso y acatamiento, más que la prestación en sí misma. En este sentido se ha pronunciado Martín-Retortillo ${ }^{18}$. Una prueba más de la importancia que se confiere a la prestación de juramento o promesa es que hasta el año 2011 se exigía, ya en el momento mismo de presentación de la instancia de solicitud de admisión al proceso selectivo de la carrera judicial, el compromiso de que se prestaría el juramento o promesa una vez superadas las pruebas. En efecto, hasta 2011 regía el Reglamento 1/1995 de la Carrera Judicial (Acuerdo de 7 de junio de 1995, del Pleno del CGPJ, por el que se ordena la publicación de los Reglamentos de la Carrera Judicial, de la Escuela Judicial, de los Jueces de Paz, de los Órganos de Gobierno de Tribunales y de los Aspectos Accesorios de las Actuaciones Judiciales, así como de la relación de ficheros de carácter personal existentes en el Consejo General del Poder Judicial). A los efectos que aquí interesan, su art. 8.3 disponía que «en el texto de las solicitudes [de acceso a las pruebas selectivas para el ingreso en la Carrera Judicial por la categoría de Juez] deberá figurar (...) el compromiso de prestar el juramento o la promesa previstos en el artículo 318 de la Ley Orgánica del Poder Judicial».

El RCJ vigente, de 2011, adapta el Reglamento a los cambios operados en las sucesivas reformas de la LOPJ. Si bien mantiene esencialmente la estructura de su antecesor, su Título I, en el que se describen todas las modalidades que, de conformidad con lo dispuesto en la LOPJ, facultan el acceso a la carrera judicial, se reduce notablemente. Como señala en su introducción, «a diferencia del Reglamento 1/1995, que de manera detallada regulaba la totalidad de los aspectos del proceso selectivo para el ingreso en la categoría de juez mediante oposición libre, el texto de 2011 ofrece una parca regulación sobre esa materia, que comienza a partir del momento en que los candidatos han optado por pertenecer a la Carrera Judicial».

La LOPJ quiere asegurarse de que «todos» los jueces y magistrados prestan juramento o promesa. Por ello, explicita que otras figuras afines también están

18 Martín-Retortillo Baquer, L. (2005), «¿Hacer constar la Religión en el Carné de Identidad? (Tribunal Europeo de Derechos Humanos: Decisión sobre admisibilidad «SofIANOpoulos, Spä̈dotis, Metallinos y Kontogiannis c. Grecia» (12 de diciembre de 2002)». Civitas Revista Española de Derecho Administrativo, 128. 
obligadas a ello. Los magistrados del Tribunal Supremo y de los Tribunales Superiores de Justicia que fuesen nombrados sin haber pertenecido con anterioridad a la carrera judicial están sometidos al juramento o promesa en los términos previstos en el art. $318 \mathrm{LOPJ}$, en el mismo acto de su toma de posesión ante las salas de gobierno respectivas, (art. 320.2 LOPJ). Obsérvese que en este caso se hace coincidir el acto de juramento o promesa con el de toma de posesión, tanto en plazo como en autoridad ante la que se llevan a cabo.

También a los magistrados eméritos se les exige juramento o promesa, aunque se les facilita al preverse su prestación en el mismo acto de juramento, siempre dentro del plazo de veinte días naturales a contar desde el siguiente al de publicación del nombramiento en el BOE (art. 265 RCJ).

Por último, cabe señalar que la Disposición Transitoria 32. ${ }^{a}$ de la LOPJ contiene un error material fruto de una modificación posterior del articulado que no fue concordada con la remisión que realiza la transitoria. El precepto remite a los arts. 318 y 460 para que los miembros de la carrera judicial y el personal al servicio de la Administración de Justicia que no hubieran prestado juramento o promesa a la entrada en vigor de la LOPJ pudieran hacerlo conforme a sus fórmulas respectivas. El art. 318 contiene la fórmula de juramento de jueces y magistrados, pero el actual art. 460 reza: «los secretarios judiciales colaborarán con la Administración tributaria en la gestión de los tributos que les sea encomendada en la normativa específica», siendo evidente que la remisión a dicho artículo es un error material.

\subsection{Jueces de paz}

Los Juzgados de Paz son órganos unipersonales ubicados en los municipios donde no existe Juzgado de Primera Instancia e Instrucción, servidos por jueces legos, es decir, personas que no pertenecen a la carrera judicial, a diferencia del resto de los órganos judiciales existentes en España. Asumen competencias de menor importancia tanto en el orden civil como en el penal. Los jueces de paz y sus sustitutos son elegidos por la mayoría absoluta del Pleno del Ayuntamiento entre las personas que, reuniendo las condiciones legales, así lo soliciten. Son nombrados por la Sala de Gobierno del Tribunal Superior de Justicia por un período de cuatro años. Cesan por las mismas causas que los jueces de carrera en cuanto les sean de aplicación. Su régimen se encuentra regulado tanto en la LOPJ (arts. 101 a 103) como en el Reglamento 3/1995, de 7 de junio, de los Jueces de Paz (RJP) (Acuerdo de 7 de junio de 1995, del Pleno del CGPJ). 
La regulación del juramento como requisito es profusa y con gran paralelismo al que el legislador impone a los miembros de la carrera judicial. En primer lugar, el juramento o promesa se configura como un requisito previo a la toma de posesión. Se trata de un acto con entidad propia, puesto que debe prestarse ante un órgano concreto, el Juez de Primera Instancia e Instrucción, que no necesariamente coincide con el órgano ante el que se deba tomar posesión a continuación, que será el que se halle ejerciendo la jurisdicción en ese momento. El RJP añade que, en caso de haber varios jueces de primera instancia o instrucción del partido, el juramento debe prestarse ante el Decano.

En segundo lugar, el plazo para la prestación de juramento o promesa vuelve a quedar indirectamente regulado. En la medida en que el juramento o promesa es un requisito previo y necesario para la toma de posesión, y que el plazo para ésta es de veinte días naturales siguientes a la fecha de publicación de su nombramiento en el Boletín Oficial de la provincia, se deduce que el juramento o promesa debe prestarse en un plazo inferior a veinte días. A semejanza de la regulación del juramento o promesa y toma de posesión de jueces y magistrados, se prevé que la Sala de Gobierno pueda prorrogar los plazos por razones justificadas («causa justa»).

En tercer lugar, el juramento o promesa es elevado a categoría de requisito indispensable sine qua non, en la medida en que la negativa a prestarlo se sanciona con la nulidad, entendiéndose como renuncia al cargo. La contundencia de la sanción a la falta de prestación de juramento o promesa es la mejor prueba de la importancia del requisito.

Se aprecia, pues, un gran paralelismo en la regulación del juramento o promesa de los jueces de paz con respecto al de los jueces y magistrados. Sin embargo, también hay alguna diferencia. Mientras que los jueces y magistrados deben prestar juramento o promesa con cada cambio de categoría o desempeño de nuevo destino, los jueces de paz únicamente prestan juramento o promesa una vez, aun cuando sean nombrados varias veces. Este matiz denota que el grado de recordatorio solemne es menor.

Por último, nótese que el art. 101 LOPJ menciona únicamente el juramento, sin referirse conjuntamente a su alternativa de promesa, mientras que el RJP emplea la cláusula «juramento o promesa» de manera indisoluble. Teniendo en cuenta que en todas las demás ocasiones en que la LOPJ se refiere al juramento, lo hace añadiendo la alternativa «o promesa», ¿hay que deducir de esta mención solitaria alguna intencionalidad del legislador? La respuesta tiene que ser negativa. Entendemos que nos encontramos ante un caso de leve descoordinación de coherencia de redacción con respecto al conjunto, fruto de las sucesivas modificaciones parciales operadas en una muy extensa ley orgánica. La redacción del 
art. 101 LOPJ no se ha modificado respecto de su redacción original en 1985, mientras que el resto de menciones, repartidas en los Libros V y VI sí se han visto envueltas en modificaciones de mayor calado, y se ha aprovechado para actualizar el requisito de juramento con su alternativa promesa, conforme a la mejor jurisprudencia y doctrina del momento. Al no haberse abordado como modificación dirigida a la regulación del juramento o promesa, se ha olvidado buscar concordancia con preceptos que no sufren modificación sustantiva.

\subsection{Suplencia y sustitución}

Un aspecto que atañe colateralmente al juramento o promesa de jueces y magistrados es el régimen de sustituciones y suplencias. Como no podía ser de otra manera, la LOPJ lo regula con minuciosidad, puesto que afecta directamente a la salvaguarda del derecho fundamental al juez ordinario predeterminado, entre otros aspectos. Dado que las suplencias y sustituciones no siempre recaen sobre jueces profesionales a quienes se exige el requisito de juramento o promesa en los términos ya expuestos, es necesario hacer alguna consideración al respecto. Dejaremos de lado las sustituciones en los órganos de gobierno tanto de tribunales como del CGPJ, en la medida en que en esos casos siempre recaen sobre miembros de la carrera judicial y por tanto no hay novedad significativa con respecto al juramento o promesa.

\subsubsection{Magistrados suplentes, magistrados y jueces sustitutos y de apoyo}

Ante necesidades de cobertura de ausencias, vacancias y de medidas de refuerzo, la LOPJ distingue entre suplencia, cuando afecta a órganos judiciales colegiados, y sustitución, aplicable a los órganos unipersonales. De ahí que la suplencia se predique únicamente de los magistrados, en sus dos categorías de magistrado y magistrado del Tribunal Supremo, mientras que la sustitución afecta no sólo a jueces y magistrados, sino también al resto de personas que pueden ejercer funciones jurisdiccionales, jueces ordinarios y jueces de paz.

En su afán por procurar que las resoluciones judiciales sean dictadas por miembros integrantes de la carrera judicial, en sintonía con el art. 298.1 LOPJ, y que la actuación de jueces sustitutos y magistrados suplentes no profesionales sea excepcional, la LOPJ prevé figuras como la comisión de servicios sin relevación de funciones, y fija un orden de prelación entre los diversos colectivos que pueden presentarse para cubrir la suplencia o la sustitución. 
Así, para los órganos colegiados se prevé, en primer lugar, la posibilidad de que los miembros de la carrera judicial voluntariamente asuman tales tareas. En su defecto, serán llamados los jueces de adscripción territorial y, a continuación, los integrantes de la carrera con menor carga de trabajo en su respectivo territorio. Solamente y de manera excepcional, cuando no resulte posible la formación de Sala con un juez o magistrado de carrera, podrá acudirse a la figura del magistrado suplente no integrante de la misma, cuyo llamamiento queda condicionado a la existencia de disponibilidad presupuestaria.

En el caso de los órganos unipersonales, habida cuenta del abuso que la práctica habitual venía haciendo de la figura del juez sustituto, la LOPJ establece un orden reglado y objetivo de los miembros de la carrera judicial que serán llamados a cubrir sustituciones (arts. 210 y 211 LOPJ).

Finalmente, el art. 216 bis LOPJ regula los refuerzos judiciales inspirado por los mismos propósitos de profesionalización y racionalización del gasto, estableciendo una mayor coordinación entre el CGPJ y el Ministerio de Justicia a la hora de determinar las necesidades y racionalizar el gasto. Se otorga preferencia a la realización de refuerzos por jueces y magistrados titulares, mediante comisión de servicio y se recoge la posibilidad de acordar la adscripción —en calidad de jueces de apoyo- de los jueces de adscripción territorial, de los jueces en expectativa de destino o de los jueces en prácticas. Sólo excepcionalmente, de manera motivada y existiendo dotación presupuestaria, podrán designarse jueces sustitutos no profesionales.

Pues bien, ¿qué consideraciones podemos hacer en torno al juramento o promesa en la regulación de la sustitución o suplencia que acabamos de esbozar? Nada hay que añadir cuando éstas son ejercidas por quienes ya ostentan la condición de jueces o magistrados, puesto que ya han tenido que prestar juramento o promesa como requisito explícito, tras su nombramiento y con cada cambio de categoría (art. 318 LOPJ). Incluso quedan a salvo los magistrados del Tribunal Supremo y de los Tribunales Superiores de Justicia que fuesen nombrados sin haber pertenecido con anterioridad a la carrera judicial, puesto que se les exige el mismo juramento o promesa previsto en el art. 318 LOPJ, en el mismo acto de su toma de posesión ante las salas de gobierno respectivas (art. 320.2 LOPJ).

Pero existe la posibilidad, por restringida que haya quedado tras la reforma de la LOPJ operada por la LO 8/2012, de 27 de diciembre, de que las suplencias o sustituciones sean ejercidas por jueces y magistrados no pertenecientes a la carrera judicial. Para salvar estos casos, el art. $99 \mathrm{RCJ}$ dispone que a quienes sean nombrados magistrado suplente o juez sustituto también se les exige juramento o promesa en los términos previstos en los artículos 318 y 321 LOPJ, y con sujeción a los mismos plazos: juramento o promesa antes de la toma de posesión, 
debiendo tomarse posesión en los tres días siguientes al juramento o promesa, y en todo caso, antes de veinte días naturales a contar desde el siguiente al de la publicación de su nombramiento en el BOE. Se dispensa del requisito del juramento o promesa quienes lo hubiesen ya prestado por haber ocupado con anterioridad el cargo de magistrado suplente o juez sustituto (art. 99 RCJ). Los magistrados suplentes tomarán posesión en el mismo acto de juramento, mientras que los jueces sustitutos lo harán en el decanato o juzgado para el que hubiesen sido nombrados o en la presidencia de la Audiencia Provincial para el supuesto de que hayan sido nombrados para actuar en todo su ámbito territorial.

Para asegurarse de la prestación del juramento o promesa por quienes van a ser nombrados magistrados o jueces sustitutos, el art. $92.2 \mathrm{RCJ}$ dispone que, confeccionadas las propuestas correspondientes del número de plazas de magistrado suplente y de juez sustituto que se consideren de necesaria provisión para cada órgano y año judicial, por parte de las Salas de Gobierno del Tribunal Supremo, Audiencia Nacional y Tribunales Superiores de Justica, para aprobación por el CGPJ, éstas se remitirán, con anterioridad al uno de febrero de cada año, al CGPJ quien, una vez aprobadas, las remitirá para su convocatoria en el BOE. Esta convocatoria se realizará con sujeción a unas bases, entre las que se incluye que las solicitudes y documentos que las acompañen habrán de contener, inexcusablemente, entre otros extremos, declaración expresa de que el candidato reúne todos y cada uno de los requisitos exigidos en la convocatoria, a la fecha en que expire el plazo establecido para la presentación de solicitudes y del compromiso de prestar el juramento o promesa previsto en el art. 318 de la LOPJ, así como declaración del compromiso de tomar posesión de la plaza para la que resultase nombrado en los plazos legalmente previstos y una vez prestado el juramento o promesa.

\subsubsection{Sustitutos de los jueces de paz}

Buena parte de estas consideraciones son aplicables a los sustitutos de los jueces de paz previstos en el art. 215 LOPJ, con la salvedad de que los jueces de paz, por su propia condición de jueces legos, no pertenecientes a la carrera judicial y por tanto habilitados para ejercer funciones jurisdiccionales sin carácter de profesionalidad y con amovilidad temporal, prestan un juramento (o promesa) diferente del exigido a los miembros de la carrera judicial. Sin embargo, a los sustitutos de los jueces de paz, no se les exige juramento o promesa. Esta es de hecho la única diferencia en su regulación, puesto que el régimen de selección, nombramiento y cese los jueces de paz y sus sustitutos es idéntico. 
¿La no exigencia de juramento o promesa a los jueces de paz sustitutos es un simple olvido? Podría ser. Pero ello indicaría un cierto menosprecio del juramento o promesa como garantía, lo cual no es coherente con el empeño del legislador en recalcar la necesidad de que los jueces de paz presten juramento, como demuestran un artículo expreso en la LOPJ (art. 101.5) y dos en el RJP (arts. 20 y 21). De ahí que sería deseable exigir de los jueces de paz sustitutos la prestación de juramento o promesa, como muestra del compromiso público con el cargo y acatamiento a la CE.

\subsubsection{Jueces en prácticas como jueces sustitutos con funciones jurisdiccionales plenas}

Como ha quedado dicho, sólo excepcionalmente, de manera motivada y existiendo dotación presupuestaria, podrán designarse jueces sustitutos no profesionales. En la consideración del juramento exigido a jueces sustitutos merece una mención especial la posibilidad excepcional de que sean nombrados jueces en prácticas. Se trata de un supuesto previsto en los arts. 210 y 216 bis LOPJ, que al regular el régimen de sustituciones y refuerzos judiciales fijan un orden de prelación otorgando preferencia a la realización de sustituciones y refuerzos por jueces y magistrados titulares, mediante comisión de servicio, y se recoge la posibilidad de acordar la adscripción — en calidad de jueces de apoyo- de jueces de adscripción territorial, jueces en expectativa de destino o jueces en prácticas.

La reforma operada por la LO 8/2012, de 27 de diciembre, supone un reconocimiento de su alto grado de capacitación, en la medida en que se les otorga preferencia de cara a cubrir sustituciones, nombrándoles el art. 210.1 LOPJ en tercer lugar del orden de prelación. Además, con la referencia del último (sexto) inciso al nombramiento de un «sustituto no profesional» sólo en caso de que las vías precedentes hayan fallado, se da a entender que los jueces en prácticas no son considerados no profesionales. Esto no deja de ser llamativo, por cuanto el ejercicio de la jurisdicción se encomienda a funcionarios en prácticas (art. 5 RCJ). Pero no cabe duda de la consideración de «cuasi-profesionalidad» de los jueces en prácticas, puesto que el Reglamento de Jueces Adjuntos (RJA) (Acuerdo de 25 de octubre de 2000, del Pleno del Consejo General del Poder Judicial, por el que se aprueba el Reglamento 2/2000 de Jueces Adjuntos) dispone que «en la oferta pública anual para el cargo de Juez sustituto se hará constar el llamamiento preferente que, en su caso, para su desempeño podrán obtener los Jueces en prácticas» (art. 11).

El RCJ desarrolla la posibilidad de que jueces en prácticas puedan ser nombrados jueces sustitutos con ejercicio de funciones jurisdiccionales: «los jueces en prácticas tuteladas podrán actuar en funciones de sustitución o refuerzo, 
conforme a lo establecido en el artículo 307.1 de la Ley Orgánica del Poder Judicial y en el presente Reglamento, a cuyo efecto, el Consejo General del Poder Judicial recabará informe del Director de la Escuela Judicial» (art. 6 RCJ).

El art. 1 RJA señala que «los aspirantes que ingresen en la Escuela Judicial para realizar el curso teórico-práctico de selección y formación inicial tendrán la consideración de Jueces en prácticas», para a continuación precisar que «el curso de selección y formación inicial incluirá un período de prácticas tuteladas que los aspirantes deberán realizar, en calidad de Jueces adjuntos, en los órganos jurisdiccionales unipersonales o colegiados que designe el Consejo General del Poder Judicial. Durante este período los Jueces adjuntos ejercerán funciones de auxilio y colaboración con los Jueces y Magistrados designados como tutores, los cuales deberán ser, en todo caso, titulares de sus respectivos órganos jurisdiccionales».

Es decir, el RJA deja claro desde su primer artículo que los jueces en prácticas tienen consideración de jueces adjuntos durante el período de prácticas tuteladas (art. 3 RJA), pero sin ejercer funciones jurisdiccionales. Sus funciones serán, antes bien, de auxilio y colaboración con sus jueces o magistrados tutores, que serán quienes asuman, con las modificaciones que estimen pertinentes, los borradores o proyectos de resolución (art. 6 RJA). Todo ello, desde su condición de funcionarios en prácticas, a todos los efectos (art. $5 \mathrm{RCJ}$ ). Para que no haya lugar a dudas, el art. 4.1 RJA dispone que «la condición de Juez adjunto no confiere los derechos propios de la Carrera Judicial».

Hasta aquí, no hay nada llamativo con respecto a cualquier curso selectivo que incorpore una fase de prácticas. Sin embargo, el Título III del RJA regula el ejercicio de funciones jurisdiccionales por los jueces en prácticas, subrayando, eso sí, en su art. 8 el carácter excepcional del ejercicio de funciones jurisdiccionales: «los Jueces en prácticas únicamente podrán desempeñar funciones jurisdiccionales si así lo acordase expresamente el Consejo General del Poder Judicial por resultar imprescindible la adopción de las medidas de apoyo judicial previstas en el artículo 216 bis de la Ley Orgánica del Poder Judicial».

El curso de selección que se desarrolla en la Escuela Judicial una vez superada la fase de oposición se compone de una parte teórica de formación multidisciplinar, un período de prácticas tuteladas en diferentes órganos de todos los órdenes jurisdiccionales (jueces adjuntos) y un período en el que los jueces en prácticas desempeñarán funciones de sustitución y refuerzo. El acceso a cada fase se condiciona a la superación de la previa, de tal modo que no se pueda comenzar práctica alguna sin haber superado la fase teórica, ni se puedan hacer labores de sustitución y refuerzo si previamente no se ha superado la fase de prácticas tuteladas. Y es que, efectivamente, se prevé el desarrollo de una tercera fase de culminación de la formación inicial en la que, tras haber aprobado el período de prácticas 
tuteladas, los futuros jueces realizarán funciones de sustitución y refuerzo en Juzgados y Tribunales, labor que será igualmente valorada por la propia Escuela Judicial tras el informe que elaborarán los Presidentes de Tribunales Superiores de Justicia, a los únicos efectos de evaluar su dedicación y rendimiento. Según el preámbulo de la LO 8/2012, de 27 de diciembre, de esta manera se pretende garantizar una formación plena y adecuada de los nuevos jueces, posibilitando una integración paulatina en el ejercicio de funciones jurisdiccionales. Podemos añadir que también es un mecanismo de asegurar la cobertura de supuestos de sustitución cumpliendo con el objetivo de la racionalización del gasto. Y, a nuestros efectos, también es un supuesto de ejercicio de funciones jurisdiccionales plenas, por lo que cabe preguntarse por el requisito del juramento o promesa.

En efecto, ¿se exige prestación de juramento o promesa a los jueces en prácticas cuando son nombrados jueces sustitutos, con carácter previo a ser investidos como jueces (previo juramento o promesa)? En caso afirmativo, prestarían dos veces el mismo juramento o promesa, dado que el art. 99 RCJ remite a los arts. 318 y 321 LOPJ para el juramento o promesa de magistrados suplentes y jueces sustitutos. Con ello podría entenderse devaluado el juramento o promesa del art. 318 LOPJ, que lo mismo valdría para jueces de carrera que para jueces no profesionales. Pero, por otra parte, si a los jueces sustitutos que no se encuentran en la Escuela Judicial, sino que acceden al cargo por otra vía, se les permite y exige la prestación del juramento o promesa del art. 318 LOPJ, podría ser discriminatorio no hacer lo propio con los jueces en prácticas, en la medida en que ejerciendo la sustitución o el refuerzo ejercen la misma potestad jurisdiccional.

El RJA resuelve esta duda por vía de la remisión. Su art. 9 dispone que «cuando por los motivos excepcionales previstos en la Ley Orgánica del Poder Judicial los Jueces en prácticas sean nombrados Jueces sustitutos o Jueces de apoyo, quedarán sujetos al régimen jurídico previsto para los mismos en dicha Ley». El art. 6.2 RCJ precisa la remisión indicando que «los jueces en prácticas tuteladas podrán actuar en funciones de sustitución o refuerzo, conforme a lo establecido en el artículo 307.1 de la Ley Orgánica del Poder Judicial y en el presente Reglamento, a cuyo efecto, el Consejo General del Poder Judicial recabará informe del Director de la Escuela Judicial».

Por lo tanto, el art. 307 LOPJ es la norma que resuelve esta cuestión: hay que entender la remisión más allá del apartado 1, puesto que la redacción del precepto ha sido modificada por el apartado quince del artículo único de la LO 8/2012, de 27 de diciembre, sin que se haya corregido la remisión en el art. 6.2 RCJ- es un pequeño detalle estético sin relevancia material, ya que un precepto de una ley orgánica siempre tendrá aplicación preferente sobre el de una norma de carácter reglamentario). Su apartado 1 señala que «superada asi- 
mismo esta fase de prácticas tuteladas, existirá un período obligatorio en el que los jueces en prácticas desempeñarán labores de sustitución y refuerzo confirme a lo previsto en los artículos 210 y 216 bis, teniendo preferencia sobre los jueces sustitutos en cualquier llamamiento para el ejercicio de tales funciones. En esta última fase ejercerán la jurisdicción con idéntica amplitud a la de los titulares del órgano judicial y quedarán a disposición del Presidente del Tribunal Superior de Justicia correspondiente, quien deberá elaborar un informe sobre la dedicación y rendimiento en el desempeño de sus funciones, para su valoración por la Escuela Judicial». A continuación el apartado 3 recalca que «los que superen el curso teórico y práctico serán nombrados jueces por el orden de la propuesta hecha por la Escuela Judicial», y el apartado 4 remata señalando que «el nombramiento se extenderá por el Consejo General del Poder Judicial, mediante orden, y con la toma de posesión quedarán investidos de la condición de juez».

A mayor abundamiento, el RHTP dedica el art. 26 a zanjar la cuestión al afirmar que «los que tengan la consideración de Jueces adjuntos jurarán o prometerán el cargo y tomarán posesión ante el Presidente del Consejo General del Poder Judicial y del Tribunal Supremo, en sesión celebrada en la sede del Consejo General del Poder Judicial. El Presidente del Consejo General del Poder Judicial podrá delegar esta competencia en el/la Presidente del Tribunal Superior de Justicia respectivo». Al igual que ocurre con el juramento en la carrera judicial, el protocolo del mismo queda plasmado reglamentariamente: «El acto se celebrará preferentemente en la sede del Consejo General del Poder Judicial, en cuyo caso los nuevos Jueces concurrirán con toga y se observarán, en función de las circunstancias, las solemnidades previstas en los artículos anteriores. De celebrarse el acto ante el/la Presidente del respectivo Tribunal Superior de Justicia, se observarán asimismo las solemnidades antes reseñadas».

En definitiva, cuando los jueces en prácticas sean nombrados jueces sustitutos, automáticamente quedarán sujetos al régimen jurídico previsto para los mismos en la LOPJ (art. 9 RJA), lo que a efectos de juramento o promesa significa que deben prestarlo en los términos previstos en los arts. 318 y 321 LOPJ, con las especificaciones del art. 26 RHTP.

El anterior RCJ de 1995 exigía un compromiso a futuro de prestar juramento o promesa en el momento de solicitar el acceso a las pruebas de ingreso a la Carrera Judicial: «en el texto de las solicitudes deberá figurar la manifestación expresa de que el interesado reúne los requisitos exigidos en la convocatoria con referencia a la fecha en que expire el plazo establecido para la presentación de aquéllas, así como el compromiso de prestar el juramento o la promesa previstos en el artículo 318 de la Ley Orgánica del Poder Judicial» (art. 8.3). 
El vigente RCJ fue redactado en 2011 y quedó aligerado del detalle sobre el acceso a la Carrera Judicial que contenía la versión anterior de 1995. En consecuencia, actualmente ni las bases, ni la convocatoria ni los impresos de liquidación de tasas para ser admitido en el proceso selectivo contienen referencia alguna en ese sentido. Ello no tiene mayor importancia material; llevando la hipótesis al extremo, la exigencia de compromiso a futuro de prestar juramento o promesa de la regulación anterior carecía de virtualidad real, en la medida en que dicha declaración no suplía el juramento o promesa previo a la toma de posesión, ni la hipotética negativa a prestarlo generaba efectos distintos a los ya previstos en cualquier caso. Pero en el campo de lo simbólico es curioso comprobar que el celo por la figura del juramento o promesa llegaba al extremo de lanzar una suerte de advertencia desde antes de adquirir la condición de aspirante a juez, sobre la importancia inexcusable de prestar el juramento o promesa, y que, por tanto, si a alguien le supusiera un problema, mejor que ni se molestara en concurrir al proceso.

A los efectos de la problemática del juramento o promesa de los jueces en prácticas que ejercen funciones de sustitución o refuerzo, la declaración del compromiso de juramento o promesa futuros sí hubiera podido entenderse como un plus con respecto a otros candidatos a ser nombrados jueces sustitutos. Pero en la medida en que la propia LOPJ ya ha incluido expresamente a los jueces en prácticas en el orden de prelación, reconociéndoles una cuasi-profesionalidad que niega a otros hipotéticos aspirantes (tampoco pertenecientes a la carrera judicial), el asunto queda definitivamente zanjado: cuando se ejerce como juez sustituto, se asume su régimen a todos los efectos.

\section{4 Órganos de gobierno}

Hasta ahora hemos examinado las peculiaridades del juramento o promesa exigido a quienes deben ejercer la potestad jurisdiccional. Pero existe una segunda modalidad de juramento o promesa en el ámbito del poder judicial, concurrente con la descrita para el ejercicio de funciones jurisdiccionales, exigida de quienes integran los órganos de gobierno del poder judicial.

El art. $122 \mathrm{CE}$ encomienda a la LOPJ la determinación de la constitución, funcionamiento y gobierno de los Juzgados y Tribunales, así como el estatuto jurídico de los jueces y magistrados de carrera, que formarán un cuerpo único, y del personal al servicio de la Administración de Justicia. Con este mandato la CE quiere evitar que otro poder del Estado, particularmente el poder ejecutivo, pueda influir directa o indirectamente sobre la independencia judicial. 
Si bien la CE dispone expresamente la existencia del CGPJ como órgano de gobierno del mismo (art. 122.2 CE), la función de gobierno de los jueces y tribunales no recae exclusivamente en el CGPJ, ya que, con subordinación al CGPJ, las Salas de Gobierno del Tribunal Supremo, de la Audiencia Nacional y de los Tribunales Superiores de Justicia ejercen funciones gubernativas y administrativas, tales como la solicitud y reparto de recursos y medios materiales y el establecimiento de normas de reparto de asuntos, de sustitución y de control de las respectivas oficinas.

\subsubsection{Consejo General del Poder Judicial}

El CGPJ es un órgano constitucional, colegiado, autónomo, integrado por jueces y otros juristas, que ejerce funciones de gobierno del poder judicial con la finalidad de garantizar la independencia de los jueces en el ejercicio de la función judicial frente a todos.

Su regulación está reservada por la CE a la LOPJ, a la que encomienda establecer su estatuto y el régimen de incompatibilidades de sus miembros y sus funciones, en particular en materia de nombramientos, ascensos, inspección y régimen disciplinario (art. 122.2 CE). La labor de gobierno del CGPJ es equiparable, en buena medida, a los actos administrativos y, al igual que estos últimos, sus resoluciones están sujetas al control de legalidad por parte de los Juzgados y Tribunales del orden contencioso-administrativo. Es importante señalar que la actuación del CGPJ no es de carácter jurisdiccional, pues este tipo de actividad está reservada, tal y como proclama el art. $117 \mathrm{CE}$, a los jueces y tribunales.

La CE fija la composición del CGPJ (art. 122.3 CE): estará integrado por el Presidente del Tribunal Supremo, que lo presidirá, y por veinte miembros nombrados por el Rey por un período de cinco años. De éstos, doce entre jueces y magistrados de todas las categorías judiciales, en los términos que establezca la ley orgánica; cuatro a propuesta del Congreso de los Diputados, y cuatro a propuesta del Senado, elegidos en ambos casos por mayoría de tres quintos de sus miembros, entre abogados y otros juristas, todos ellos de reconocida competencia y con más de quince años de ejercicio en su profesión.

Este esquema procura reforzar la defensa de la independencia judicial que el CGPJ tiene encomendada. La regulación que la LOPJ desarrolla ha sido modificada por la Ley Orgánica 4/2013, de 28 de junio, de reforma del Consejo General del Poder Judicial, por la que se modifica la Ley Orgánica 6/1985, de 1 de julio, del Poder Judicial.

A los efectos de análisis de juramento o promesa que nos ocupa, es preciso distinguir entre el Presidente y los Vocales del CGPJ. 
- Presidente del CGPJ

El Presidente del Tribunal Supremo lo es del CGPJ, y viceversa (art. 122.3 CE). Es la primera autoridad judicial de la Nación y ostenta la representación del Poder Judicial y del órgano de gobierno del mismo, correspondiéndole el tratamiento y los honores inherentes a tal condición (art. 585 LOPJ).

El Presidente del CGPJ es designado por el Pleno del Consejo en su sesión constitutiva, elegido entre miembros de la carrera judicial o juristas de reconocida competencia. Para ser elegido Presidente del TS y del CGPJ es necesario ser miembro de la carrera judicial con la categoría de magistrado del Tribunal Supremo y reunir las condiciones exigidas para ser Presidente de Sala del mismo, o bien ser un jurista de reconocida competencia con más de veinticinco años de antigüedad en el ejercicio de su profesión (art. 586.1 LOPJ).

El Presidente del TS es nombrado por el Rey mediante Real Decreto refrendado por el Presidente del Gobierno. Presta juramento o promesa ante el Rey y toma posesión de su cargo ante el Pleno de dicho Alto Tribunal (art. 586.4 y 5 LOPJ).

El RHTP regula el acto de juramento o promesa y toma de posesión del Presidente del TS y del CGPJ en su art. 22. El acto consistirá en la prestación de juramento o promesa ante el Rey y la toma de posesión, en audiencia pública, ante la Sala de Gobierno y los Plenos del TS y del CGPJ.

En la ordenación del acto se observarán las normas que se contemplan en el art. 17 RHTP para el Acto de apertura de Tribunales en el Tribunal Supremo. La organización, precedencias y distribución de lugares en dicho acto se efectuará por la Sala de Gobierno del Tribunal Supremo. El Reglamento recogerá las directrices básicas que deriven del acuerdo que, sobre dicha organización, apruebe su Sala de Gobierno.

- Vocales del CGPJ

Al igual que su Presidente, los Vocales del CGPJ son nombrados por el Rey mediante Real Decreto y toman posesión de su cargo prestando juramento o promesa ante el Rey (art. 569.1 LOPJ).

La diferencia con el régimen del Presidente a estos efectos radica en la toma de posesión. En el caso del Presidente del TS y del CGPJ se señala únicamente un aspecto formal: debe realizarse ante el Pleno del TS. La toma de posesión de los Vocales del CGPJ, en cambio, se vincula a otro hecho, puesto que debe celebrarse a continuación la sesión constitutiva. Ambos actos (toma de posesión y sesión constitutiva) tendrán lugar dentro de los cinco días posteriores a la expiración del anterior Consejo, salvo en el supuesto previsto en el artículo 570.2 LOPJ (art. 569.2 LOPJ). 
En cuanto a la fórmula del juramento o promesa que deben prestar tanto el Presidente del TS y del CGPJ, como los Vocales del CGPJ, nada se explicita en la LOPJ ni en las normas que lo desarrollan. De modo que se sobreentiende que se aplica la fórmula genérica del art. 318 LOPJ

Sin embargo, llama la atención que a los presidentes y miembros electos de las Salas de Gobierno de los órganos jurisdiccionales, como veremos a continuación, se les exija juramento o promesa de la obligación de guardar secreto de las deliberaciones (art. 22 f) RHTP para los presidentes, arts. 25 RHTP y 49 ROGT para los miembros electos), sin que tal referencia se explicite ni para el Presidente ni para los Vocales del CGPJ. La reciente redacción del ROGT (2000) y del RHTP (2005) no permite pensar que se trate de un descuido de concordancias normativas, puesto que especialmente en el RHTP se regula con mucho detalle el acto de juramento o promesa y toma de posesión del Presidente del TS y del CGPJ así como de los Vocales del CGPJ. Cabría preguntarse por las razones de esta omisión, y si no sería deseable incluir la referencia a la obligación de guardar secreto de las deliberaciones del Consejo, para salvaguardar el sentido colegial de las decisiones, en la medida en que la revelación de las deliberaciones sólo puede ser relevante si se busca conocer el parecer individual de los miembros del Consejo (a la manera en que ocurre con los votos particulares en las Sentencias), aspecto contradictorio con la naturaleza colegial del órgano.

\subsubsection{Salas de gobierno de los órganos jurisdiccionales}

Como ha quedado dicho, las Salas de Gobierno del Tribunal Supremo, de la Audiencia Nacional y de los Tribunales Superiores de Justicia ostentan también competencias en materia de gobierno interno de los tribunales, si bien, en última instancia sus resoluciones son revisables por el CGPJ. Asimismo, las Audiencias Provinciales y los Juzgados también cuentan con atribuciones en materia de gobierno.

A grandes rasgos, las Salas de Gobierno del Tribunal Supremo y de la Audiencia Nacional están constituidas por el Presidente de dichos órganos, que las presiden, por los Presidentes de las Salas en ellos existentes y por un número de magistrados igual al de éstos (art. 149.1 LOPJ).

A su vez, las Salas de Gobierno de los Tribunales Superiores de Justicia están constituidas por el Presidente de éstos, que las preside, por los Presidentes de las Salas en ellos existentes, por los Presidentes de las Audiencias Provinciales de la Comunidad Autónoma, y por un número igual de magistrados o jueces, elegidos por todos los miembros de la carrera judicial destinados en ella. Al menos uno de los componentes de la Sala será de la categoría de juez, salvo que no hubiera candidatos de dicha categoría. Además de éstos se integran también, con la 
consideración de miembros electos a todos los efectos, los decanos que de conformidad con lo establecido en el art. 166.3 LOPJ hayan sido liberados totalmente del trabajo que les corresponda realizar en el orden jurisdiccional respectivo (art. 149.2 LOPJ).

Los miembros electivos de las Salas de Gobierno se renovarán en su totalidad cada cinco años, computados desde la fecha de constitución de aquéllas. Transcurrido dicho plazo, la Sala de Gobierno continuará en el ejercicio de sus funciones hasta la fecha de constitución de la nueva (art. 150 LOPJ). La LOPJ regula profusamente el procedimiento de elección de miembros de las Salas de gobierno (art. 151 LOPJ).

Por lo que se refiere a las funciones que desempeñan las Salas de Gobierno en sus respectivos tribunales, el art. 152 LOPJ menciona, entre otras, la aprobación de las normas de reparto de asuntos, el establecimiento objetivo de los turnos, el ejercicio de facultades disciplinarias sobre magistrados, la propuesta al CGPJ de magistrados suplentes y de la lista de jueces sustitutos, $y$, a los efectos que interesan a este trabajo, la recepción del juramento o promesa legalmente previsto de los magistrados que integran los respectivos tribunales y darles posesión.

Las Salas de Gobierno deben reunirse periódicamente (art. 153.1 LOPJ), y se habilita su constitución por el Presidente y dos miembros para las actuaciones no decisorias de carácter formal, citándose como ejemplo de tales actuaciones la recepción de juramento o promesa o la toma de posesión de jueces y magistrados u otras de carácter análogo (art. 153.3 LOPJ). En los demás casos, para su válida constitución, se requerirá la presencia, al menos, de la mayoría de sus miembros, que deberán ser citados personalmente con veinticuatro horas de anticipación como mínimo (art. 153.4 LOPJ).

Un examen más pausado del juramento o promesa en relación con los órganos de gobierno jurisdiccionales nos lleva a algunas consideraciones. La primera se refiere a la cita expresa de la recepción del juramento o promesa de jueces y magistrados como una función de la Sala de Gobierno (art. 152.1.11..$^{\circ}$ LOPJ). Ello supone categorizar la recepción de juramento o promesa como una función de gobierno.

Una segunda consideración, correlativa a la primera, es el tratamiento que recibe esa función de recibir el juramento o promesa. El art. 153.3 LOPJ es claro: se trata de una actuación no decisoria de carácter formal, sin que quepa duda alguna al respecto, por cuanto está citada expresamente («tales como la recepción de juramento o promesa o la toma de posesión de jueces y magistrados $u$ otras de carácter análogo»). El art. 8.1 del Reglamento de los Órganos de Gobierno de los Tribunales (ROGT, Reglamento 1/2000, de 26 de julio, del Consejo General del Poder Judicial), lo corrobora prácticamente en los mismos términos. La consecuencia de ello es que para ejercer la función de recepción de juramento o prome- 
sa basta un quórum de constitución de Sala mínimo (Presidente y dos miembros), mientras que «en los demás casos, para su válida constitución se requerirá la presencia, al menos, de la mayoría de sus miembros, que deberán ser citados personalmente con 24 horas de anticipación como mínimo» (art. 153.4 LOPJ).

El Título III de la LOPJ sólo contiene esas dos menciones expresas del juramento o promesa en relación con las salas de gobierno, es decir, sólo lo aborda desde la perspectiva de la recepción del juramento o promesa de terceros. Pero hay que plantearse si los propios Presidentes y miembros de las Salas de Gobierno están sometidos a obligación de juramento o promesa. La respuesta, afirmativa, la encontramos en dos normas de rango reglamentario: el ROGT y el RHTP.

Por una parte, el art. 49 ROGT dispone que en el momento de constitución de las Salas de Gobierno, sus miembros electos prestarán juramento o promesa de cumplir fielmente las obligaciones de su cargo y de guardar secreto de las deliberaciones de la Sala de Gobierno. Llama la atención la reserva de la obligación a los miembros electos (lógico, puesto que se sobreentiende que el juramento o promesa de fiel desempeño del cargo por parte de los miembros natos ya incluye implícitas las obligaciones derivadas de su pertenencia nata a la Sala de Gobierno) y la imposición de una nueva obligación, la de guardar secreto de las deliberaciones de la Sala de Gobierno (recuerda al juramento o promesa que prestan los ministros). Recordemos que el ROGT vigente es del año 2000, por lo que se presume que el CGPJ autor del reglamento la considera acorde a los tiempos.

Por otra parte, el art. 22 RHTP regula con prolijo detalle el acto de toma de posesión de quienes ejerzan el cargo de Presidente de la Audiencia Nacional, de los Tribunales Superiores de Justicia, de Sala, Audiencias Provinciales, y de Magistrados de Tribunales y Audiencias. El acto se celebrará en audiencia pública ante la Sala de Gobierno. Se dispone expresamente que el acto de toma de posesión de magistrados nombrados para un primer destino en la carrera judicial o cuando se trate de un ascenso de categoría, irá acompañado del juramento o promesa. Se introduce la figura del padrino, que será un miembro del propio tribunal si bien, excepcionalmente, el Presidente podrá autorizar que lo sea un magistrado destinado en otro tribunal, aun cuando esté en situación de servicios especiales, o un juez o magistrado emérito o jubilado.

De manera similar, el art. 25 RHTP incide en la obligación de prestar juramento o promesa de los miembros electos de las Salas de Gobierno en el momento de su constitución, juramento o promesa de cumplir fielmente las obligaciones de su cargo y también de guardar secreto de las deliberaciones de la Sala de Gobierno. Se dispone una cierta solemnidad, al prescribirse que el juramento o promesa se preste ante el/la Presidente y los miembros natos, en audiencia pública y con toga. El mismo procedimiento se aplicará para las renovaciones parcia- 
les, así como en el caso de Jueces Decanos que se integren como miembros natos en las Salas de Gobierno.

Por último, el art. 5.1 c) ROGT recoge una función adicional de las Salas de Gobierno de los Tribunales Superiores de Justicia, en Pleno o en Comisión, con respecto al juramento o promesa: la recepción del que legalmente se pueda exigir a los abogados, procuradores y graduados sociales, cuando así se prevea en las disposiciones corporativas aplicables.

\section{CONCLUSIONES}

El juramento o promesa cuenta con una profusa regulación en el ámbito del poder judicial. Se puede afirmar que el juramento o promesa exigido a jueces y magistrados es, tras el juramento exigido al Rey y al Príncipe de Asturias en el art. $61 \mathrm{CE}$, el de mayor categoría y de más difícil modificación del ordenamiento español (art. $168 \mathrm{CE}$ ), acaso reflejo de la inamovilidad de quienes deben prestarlo. De ello da cuenta el que buena parte de su regulación se encuentre detallada en una norma con rango de ley orgánica, en la que queda fijada la fórmula literal; que los posteriores desarrollos estatutarios y reglamentarios insistan en el detalle hasta incorporar aspectos de protocolo; que se conciba el acto de prestación de juramento o promesa como un acto independiente y previo al de toma de posesión, ante autoridad y plazo distintos de los de la toma de posesión; que se exija no sólo al ingreso en la carrera judicial, sino también en cada ascenso de categoría; que el Presidente del Tribunal o Audiencia ante quien se presta esté obligado a comunicar al CGPJ la prestación del juramento o promesa, o en su caso el transcurso del tiempo sin hacerlo; y, especialmente, la dureza de la sanción de nulidad, entendida como renuncia al cargo y a la carrera judicial, en caso de incumplimiento.

Con algunos matices, el mismo o similar juramento o promesa es exigido a los restantes miembros del poder judicial que desempeñan funciones jurisdiccionales aun sin pertenecer a la carrera judicial. Así, se exige de los jueces de paz, que desempeñan tales funciones con carácter estable. Al igual que el juramento o promesa de los jueces de carrera, el de los jueces de paz se configura como requisito previo a la toma de posesión con entidad propia, pues debe prestarse ante autoridad y en plazo diferentes a la toma de posesión. La negativa a prestarlo se sanciona con la nulidad, entendiéndose como renuncia al cargo. Sin embargo, se presta una única vez, sin exigirse su renovación aun cuando sean nombrados varias veces. 
También se exige el juramento de quienes están llamados a desempeñar funciones jurisdiccionales de manera circunstancial o limitada en el tiempo, como es el caso de los magistrados suplentes, magistrados y jueces sustitutos y de apoyo y jueces en prácticas cuando ejercen como jueces sustitutos con funciones jurisdiccionales plenas. En estos casos, nada hay que añadir respecto del juramento o promesa cuando las funciones de suplencia o sustitución recaen sobre jueces o magistrados de carrera, que quedan dispensados del requisito por haber prestado el juramento o promesa anteriormente. Pero cuando las suplencias o sustituciones sean ejercidos por jueces y magistrados no pertenecientes a la carrera judicial, se les exige el mismo juramento que prestan éstos, con idénticas condiciones sobre plazos, autoridad ante la que hacerlo y consecuencias de la negativa. Se llega incluso a asegurar de antemano la prestación de juramento o promesa exigiendo el compromiso de hacerlo en el momento de la presentación de la solicitud, mucho antes del nombramiento. Curiosamente, a los sustitutos de los jueces de paz no se les exige un juramento o promesa de manera expresa. En cuanto al caso excepcional de los jueces en prácticas cuando ejercen como jueces sustitutos con funciones jurisdiccionales plenas, hay que destacar que el juramento o promesa exigido es independiente, aunque sea idéntico, del que posteriormente se verán obligados a prestar antes de su toma de posesión como jueces de carrera.

Junto con el juramento o promesa exigido para el ejercicio de la potestad jurisdiccional se regula un segundo tipo de juramento o promesa referido a los miembros del poder judicial que desempeñan funciones en los órganos de gobierno, el CGPJ y las Salas de Gobierno de los órganos jurisdiccionales. Este segundo tipo de juramento es concurrente con el descrito anteriormente. El juramento o promesa de los miembros del CGPJ es el mismo exigido por el art. 318 LOPJ a los miembros de la carrera judicial, con la nota característica de que se presta ante el Rey. En cambio, el juramento o promesa exigido a los miembros de Salas de gobierno incluye la cláusula de guardar secreto de las deliberaciones de éstas.

Más allá del gusto por las formas solemnes y la tradición, las razones para una regulación tan precisa del juramento o promesa hay que buscarlas en la voluntad de hacer de este mecanismo una garantía adicional de la independencia del poder judicial en su fundamental tarea de administrar la justicia. Desde la perspectiva de los destinatarios del juramento o promesa de jueces y magistrados, que no son otros que los ciudadanos, supone asimismo una garantía de refuerzo del plus de fidelidad activa a la Constitución por parte de quienes tienen encomendada su aplicación y en quienes se ven obligados a confiar el ejercicio de la potestad jurisdiccional. 
Title:

OATH OR AFFIRMATION AT THE JUDICIARY

\section{Summary:}

1. PRELIMINARY NOTIONS ON THE OATH OR AFFIRMATION AT THE JUDICIARY. 2. OATH OR AFFIRMATION OF JUDGES AND MAGISTRATES. 2.1 The bench. 2.2 Justices of the peace. 2.3 Replacement and substitution. 2.3.1 Replacement and support magistrates and judges. 2.3.2 Replacement of Justices of the peace. 2.3.3 Intern judges as substitute judges with full jurisdictional powers. 3. GOVERNING BODIES. 3.1 General Council of the Judiciary. 3.2 Governing bodies of jurisdictional courts. 4 . CONCLUSIONS

\section{Resumen:}

El juramento o promesa exigidos a jueces y magistrados se regula con intensidad en el ordenamiento español. Tras el juramento regio (art. $61 \mathrm{CE}$ ), es el de mayor categoría, puesto que queda fijado en norma con rango de ley orgánica (LOPJ) y cuenta con un prolijo desarrollo normativo. Ello se debe a la función de doble garantía que se asigna al juramento en el ámbito del poder judicial. Desde la perspectiva de quienes están obligados a prestarlo, opera como refuerzo de su independencia. Desde la perspectiva de los ciudadanos destinatarios del mismo, supone un refuerzo del plus de fidelidad activa a la Constitución.

En este trabajo se analizan, primero, las particularidades del juramento que deben prestar los miembros de la carrera judicial, con especial atención a aspectos como su fórmula, los detalles de protocolo exigidos normativamente, su consideración como un acto independiente y previo al de toma de posesión, ante autoridad y plazo distintos, la exigencia de prestación no sólo al ingreso en la carrera judicial, sino también en cada ascenso de categoría, la obligación de comunicación de su prestación por parte de la autoridad ante quien se presta, o en su caso el transcurso del tiempo sin hacerlo, o la dureza de la sanción de nulidad, entendida como renuncia al cargo y a la carrera judicial, en caso de incumplimiento.

Con algunos matices, el mismo o similar juramento o promesa es exigido a los restantes miembros del poder judicial que desempeñan funciones jurisdiccionales aun sin pertenecer a la carrera judicial. Así, se exige de los jueces de paz, que desempeñan tales funciones con carácter estable. El juramento o promesa de los jueces de paz también se configura como requisito previo a la toma de posesión con entidad 
propia y la negativa a prestarlo se sanciona con la nulidad, si bien se presta una única vez.

También se exige de quienes están llamados a desempeñar funciones jurisdiccionales de manera circunstancial o limitada en el tiempo, como es el caso de los magistrados suplentes, magistrados y jueces sustitutos y de apoyo y jueces en prácticas cuando ejercen como jueces sustitutos con funciones jurisdiccionales plenas. En estos casos, cuando las suplencias o sustituciones sean ejercidas por jueces y magistrados no pertenecientes a la carrera judicial, se exige el mismo juramento que prestan los jueces profesionales, llegándose incluso a asegurar de antemano que se prestará en el momento de la presentación de la solicitud del cargo, mucho antes del nombramiento. En el caso excepcional de los jueces en prácticas cuando ejercen como jueces sustitutos con funciones jurisdiccionales plenas, el juramento o promesa es independiente, aunque sea idéntico, del que posteriormente se verán obligados a prestar antes de su toma de posesión como jueces de carrera.

Finalmente, un segundo tipo de juramento o promesa es el referido a los miembros del poder judicial que desempeñan funciones en los órganos de gobierno, el CGPJ y las Salas de gobierno de los órganos jurisdiccionales. Se trata de un juramento concurrente con el descrito.

\section{Abstract:}

The oath or affirmation of office required from members of the judiciary is intensely regulated in the Spanish legal system. Second only to the royal oath contained in art. 61 of the Spanish Constitution, it is undoubtedly the highest-ranking oath, since it is set in an organic law (LOPJ, Organic Law for the Judiciary Power) and enjoys profuse detail in further statutes. This is due to a double-guarantee role assigned to the oath of office in the Judiciary. From the oath-taker's perspective, the oath reinforces judicial independence. From the oath-receivers' perspective, the oath reinforces active constitutional loyalty.

This paper deals, first, with the specificities of the oath of professional judges, paying attention to aspects such as the formula, regulated formalities, its consideration as an independent act different from the inauguration act, the need to confirm the oath at each career promotion and not just upon entering service, the obligation of the oath-taking authority to communicate its successful or unsuccessful completion, or the harsh sanction of nullity, identified with resignation of post, in case of failure to take the oath.

Second, with some nuances, the same applies to the remaining members of the judiciary who hold jurisdictional powers but do not per- 
tain to the professional judges' career. Justices of the peace exert such powers in a stable manner. Their oath is also an independent act for their inauguration, and failure to take it also results in nullity, but the oath is only required upon the first appointment.

An oath is also required from substitute, replacement and intern judges. When such a role falls upon non-professional judges, they are required to take the same oath professional judges take. This requirement is all the more stressed by the fact that candidates to hold substitute or replacement roles must commit to taking the oath upon applying for the position. When exceptionally permitted to exert jurisdictional powers, intern judges are required to take the same oath professional judges take, regardless their obligation to take the same oath once they are admitted to the professional career.

Finally, another type of oath or affirmation is that required from members of the judiciary in their role within governing bodies, namely the General Council for the Judiciary (Consejo General del Poder Judicial, CGPJ) or governing bodies of jurisdictional courts. Such an oath converges with the regular judicial oath.

Palabras clave:

Juramento, promesa, garantía, fidelidad constitucional, poder judicial.

Keywords:

Oath, affirmation, guarantee, constitutional loyalty, judiciary. 